\title{
Factors Associated with Adherence to Blood Glucose Test among Diabetes Mellitus Patients at Prof. Dr. W. Z. Johannes Hospital, Kupang
}

\author{
Dessy Nelciani Timuneno, Deviarbi Sakke Tira, Imelda F. E Manurung
}

Epidemiology and Biostatistics, School of Public Health, Nusa Cendana University, Kupang

\begin{abstract}
Background: Blood glucose level test for the Diabetes Mellitus patients is a procedure to monitor blood glucose level control and early detect complication of the disease. This study aimed to investigate the factors associated with adherence to blood glucose test among diabetes mellitus patientsat Prof. dr. W. Z. Johannes Hospital, Kupang.

Subjects and Method: This was an analytic study withcross sectional study. A total of 93 Diabetes Mellitus patientswho had attended Internal Medicine Clinic at Prof. dr. W. Z. Johannes Hospital, Kupang, for at least 10 years, were sampled for this study. This sample consisted of 45 patients who adhered and 48 patients did not adhere to blood glucose test. Association of variables under study was analyze by chi square test.

Results: There is a positive but weak relationship between adherence to blood glucose test and distance to health care facility $(C=0.28 ; p=0.005)$, as well as family support $(C=0.21 ; p=0.043)$.

Conclusion: the health care authority should consider providing health care service for diabetes mellitus patients as close as possible to their home. In addition families of the patient are suggested to support their family members with diabetes mellitus in controlling blood glucose regularly.
\end{abstract}

Keywords: adherence, blood - glucose level, diabetes mellitus.

\section{Correspondence:}

Dessy Nelciani Timuneno. Epidemiology and Biostatistics, School of Public Health, Nusa Cendana University, Kupang.

\section{BACKGROUND}

Diabetes Mellitus (DM) or diabetes is a condition of excessive glucose in the blood, caused hormone secretion interference called insulin (too little insulin or an ineffecttive insulin). Insulin is produced by the pancreas gland and controls the entry of glucose into the cells, and converts glucose into energy for the needs of normal cells. Diabetes Mellitus is a metabolic disease that is associated with the pancreas gland, occurs when excess blood glucose cannot enter the body's cells as a result glucose builds up in the blood and then excreted through the urine.

World Health Organization (WHO) estimates that 177 million people worldwide have diabetes. Number of people with diabetes will increase over 300 million in 2025 because it is influenced lifestyle of the world that will have an impact on the quality of human resources and increased health cost. According to data estimates IDF (International Diabetes Federation), presented data numbers of diabetes cases in Indonesia based on the results of the survey in 2008 ranks fourth highest in the world after China, India and the United States of 8.4 million jiwa. This number is expected to rise to 21.3 million in 2030. According to Dr. Paul Zimmert, director the International Diabetes Institute in Victoria, United foresees that DM would be the most devastating epidemic in human history. 
Based on data obtained from Prof. dr. Z. W. Johannes hospital, Kupang recorded number of people with diabetes in 2010 as in 2827, the year 2011 as many as 3093 people, while in January 2012 - September 2012 as many as 1421 people. Poly DM data in the number of cases recorded in 2010 as in 1846 with a history of old cases $96.21 \%$, in 2011 as many as 2317 cases with long case histories $91.58 \%$. While in the year 2012 was recorded as many as $3147 \mathrm{DM}$ patients with a history of old cases as much as $97.52 \%$. The total cases who have experienced complications (781 patients), i.e. $14.34 \%$ of neurological function, hypertension $76.56 \%$, $5.12 \%$ impaired renal function, stroke $0.38 \%$ and others $3.60 \%$.

Most of DM patients not aware they were being targeted by a great danger. This is because gesture DM sometimes appears as a symptom that can be considered as a matter of course. Whereas three characterristics of diabetes that need to be aware when they appear simultaneously in an unnatural thirst, frequent urination and weight loss with unclear reason 5 .

Diabetes Mellitus including diseases cannot be cured, that may be done to control so that the sufferer can maintain their quality of life. By knowing the symptoms of Diabetes Mellitus early disease control efforts can be done to prevent other complications. One management in patients with DM is check blood glucose levels through laboratory tests for diagnosing and monitoring of the incidence of specific complications can arise as a result of the DM disease. DM complications arise acutely or occur suddenly and also chronic or slowly as result of DM is not controlled well and prolonged.

Attempt to keep blood glucose close to normal also depends on the knowledge of people about the disease. Knowledge some- one closely related to the behavior to be taken, because knowledge patients have reason and basis for determining an option. Cognitive domain knowledge is very important for the formation of a person's actions or behavior. DM patients knowledge helps people with diabetes treatment during their life.

More and more people understand the disease, so the patients to better understand how to alter their behavior and why it was necessary. Results of research conducted Semana (2011) at the General Hospital of Makassar Baji Labuang in 43 respondents showed a significant relationship between the level of knowledge about the disease and complications of patients with patient treatment compliance measures.

Patient education is generally regarded as an important component of diabetes management. However, analysis of the role of education and knowledge in the control of diabetes is still limited. Patients who have a good knowledge of diabetes, but a change in the control of diabetes and other clinical parameters are not necessarily followed.

Family is an important role in determining how or nursing care required by patients at home so it will decrease the recurrence rate of ${ }^{10}$. The study states that the family has a strategic function in reducing the recurrence rate, improve the independence and quality of life and patients are able to readapt to society and social life 11.

DM disease prevention efforts through examination of blood glucose levels are carried by each patient is different so it is one of the factors causing the high rate of complications. It can be seen from the number of Poly DM patients at hospitals Prof. dr. Z. W. Johannes hospital, Kupang every year. It also had number patient complications cases with quite high and most patients with complications of long 
Indonesian Journal of Medicine (2016), 1(1): 12-19 https://doi.org/10.26911/theijmed.2016.01.01.02

lines. Therefore, it is important to know the causes in order to control and prevention of diabetes that do work effectively so as to prevent complications. Based on the above description, researchers interested in conducting research with the title: "Factors associated with noncompliance with Diabetes Mellitus in examinations of blood glucose levels at Prof. dr. Z. W. Johannes hospital, Kupang in 2013 ".

The research objective was to determine the relationship of education, knowledge, distance health services and family support to non-compliance with DM in examinations of blood glucose levels.

\section{SUBJECTS AND METHOD}

This type of research was analytic survey with cross sectional design where the dependent and independent variables observed at the same time12.

This study was conducted at Prof. dr. Johannes W. Z. hospital, Kupang on outpatient in Poly Diabetes Mellitus which was patients who suffer diabetes $\leq 10$ years old, with 93 patients were taken using purposive sampling technique. Data collection was using a questionnaire (education, knowledge, distance to health services and family support). The research was conducted for one month, April 2013 to May 2013.

Processing data using SPSS program with chi square analysis methods and subsequently presented in table and narration.

Univariate analysis was used to describe the characteristics of the respondent in a frequency distribution table. Bivariate analysis would be aimed to examine the relationship of dependent and independent variables using chi square analysis.

If the results of chi square showed relationship, so continue contingency coefficient test to see the closeness between the variables 13 .

\begin{abstract}
RESULTS
Prof. dr. Z. W. Johannes hospital, Kupang is the referral hospital of type $B$ non-education, belonging to the Provincial Government of East Nusa Tenggara (NTT), which have health care for the whole society. It has a land area of $51670 \mathrm{~m}^{2}$ and a building area of $42418 \mathrm{~m}^{2}$.
\end{abstract}

To support the health service Prof. dr. Z. W. Johannes hospital, Kupang provide various facilities for the needs of medical services. Staff data of Prof. dr. Z. W. Johannes Hospital, Kupang, consisting 999 Civil Servants (PNS) and 178 non-Civil Servants / honorary staff.

DM education Polyclinic opened on April 15, 2008. The number staffs in Poly DM Educational is one general practitioner, one D3 nurse, one D4 nutritionist.

Poly Educational DM Schedule every Saturday include: 1) Counseling held on Saturday in the first week in every month, 2) Sport/ gymnastics was held on Saturday in the second week, 3) Counseling resumed on Saturday in the third week, 4) Sports/ gymnastics continued on the Saturday in the fourth week.

Blood pressure and weighed patients who come to Poly DM Education will be measured. The nurse then records the complaints of patients, the results of balanced body weight and blood pressure measurements as well as the results of laboratory tests on the patient status. DM patients are going to the doctor for checkup, given advice, prescriptions and laboratory blanks for further blood tests. The population in this study was all patients with Diabetes Mellitus who are long visitors in Poly DM Prof. dr .W. Z. Johannes hospital, Kupang in 2012 which amounted to 3069 patients. A sample used purposive sampling technique. 
Univariate analysis of respondents include age, gender, occupation and place of residence.The bivariate analysis was to see the relationship of all the dependent variables, from the results of the bivariate analysis $\mathrm{p} \leq 0.05$ showed the relationship between independent and dependent variables and can be continued to test contingency coefficient to see the closeness between the variables.

Table 1. Frequency distribution of respondents by age, gender, occupation at Prof. dr. Z. W. Johannes Hospital, Kupang.

\begin{tabular}{llcc}
\hline Characteristics & Category & Total & \% \\
\hline Age & $<30$ & 1 & 1.1 \\
& $30-34$ & 1 & 1.1 \\
& $35-39$ & 0 & 0 \\
& $40-44$ & 5 & $5 \cdot 4$ \\
& $45-49$ & 9 & 9.7 \\
& $50-54$ & 14 & 15.1 \\
Gender & $55-59$ & 15 & 16.1 \\
& $60-64$ & 22 & 23.7 \\
Occupation & $65+$ & 26 & 28.0 \\
& Male & 43 & 46.2 \\
& Female & 50 & 53.8 \\
& Peasant & 1 & 1.1 \\
& Entrepreneur & 2 & 2.2 \\
& Private & 3 & 3.2 \\
Address & Students & 1 & 1.1 \\
& Housewives & 36 & 38.7 \\
& Retirements & 28 & 30.1 \\
& Civil Servants & 22 & 23.7 \\
& Out of City & 6 & 6.5 \\
\hline
\end{tabular}

Table 2. Analysis factors associated with adherence to blood glucose test among diabetes mellitus patients at Prof. Dr. W. Z. Johannes Hospital, Kupang

\begin{tabular}{|c|c|c|c|c|c|c|c|}
\hline \multirow{3}{*}{$\begin{array}{l}\text { Independent } \\
\text { Variables }\end{array}$} & & \multicolumn{4}{|c|}{$\begin{array}{l}\text { Non-Adherence Examination Blood } \\
\text { Glucose }\end{array}$} & \multirow{3}{*}{$\mathbf{C}$} & \multirow{3}{*}{$\mathbf{p}$} \\
\hline & & \multicolumn{2}{|c|}{ Non adherence } & \multicolumn{2}{|c|}{ Adherence } & & \\
\hline & & $\mathbf{n}$ & $\%$ & $\mathbf{n}$ & $\%$ & & \\
\hline \multirow{3}{*}{ Education } & Low & 16 & $53 \cdot 3$ & 14 & 46.7 & \multirow{3}{*}{0} & 0.819 \\
\hline & High & 32 & 50.8 & 31 & 49.2 & & \\
\hline & Poor & 21 & 53.3 & 17 & 44.7 & & 0.839 \\
\hline \multirow{2}{*}{ Knowledgeable } & Sufficient & 19 & 48.7 & 20 & 51.3 & \multirow[t]{2}{*}{0} & \\
\hline & Decent & 8 & 50.0 & 8 & 50.0 & & \\
\hline \multirow{2}{*}{$\begin{array}{l}\text { Distance to Health } \\
\text { Care Facility }\end{array}$} & Distant & 35 & 63.6 & 20 & 36.4 & \multirow{2}{*}{0.28} & \multirow[t]{2}{*}{0.005} \\
\hline & Nearby & 13 & 34.2 & 25 & 65.8 & & \\
\hline \multirow{2}{*}{ Family Support } & Doesn’t Support & 26 & 63.4 & 15 & 36.6 & \multirow{2}{*}{0.21} & \multirow[t]{2}{*}{0.043} \\
\hline & Support & 22 & 42.3 & 30 & 57.7 & & \\
\hline
\end{tabular}

Based on the results of statistical analysis showed that the variables that have a relationship were distance health care $(\mathrm{p}=$
0.005) with a level of closeness to the medium level, family support $(\mathrm{p}=0.043)$ with a level of closeness to the weak level. While the variables 
Indonesian Journal of Medicine (2016), 1(1): 12-19 https://doi.org/10.26911/theijmed.2016.01.01.02

that do not have a relationship were education $(\mathrm{p}=0.819)$ and knowledge $(\mathrm{p}=0.839)$.

\section{DISCUSSION}

Education is all the efforts that is planned to influence others either individual, group, or community, so they do what is expected by the educational actors.

The expectation result of health education is on healthy behavior to maintain and improve the health conducive. The results showed no educational variables significantly related to non-compliance with Diabetes Mellitus in examinations of blood glucose levels $\mathrm{p}=0.819$ ). In this study, there was no relationship of education level of poor adherence of patients with Diabetes Mellitus in examinations of blood glucose levels caused by patients who have a low level of formal education meant $\leq$ SMP (30 respondents), most of them got family supports (63.3\%), so despite having low education and receives get family support, capable to improving high motivation in the patient to check blood glucose levels.

In addition, based on interviews of 93 respondents 38 respondents (40.8\%) who said the reason they dutifully carry out checks of blood glucose levels because of their fear of the involvement of the complications that can arise from diabetes and of these 38 respondents there were 21 (55.3\%) of respondents with low education. However, based on the results of the research, respondents with low education actually has the highest distribution of respondents who do not comply checks of blood glucose levels, it is possible because the less educated respondents are mostly Housewife (86.7\%), so that more preoccupied with various chores. Likewise with highly educated respondents, the highest distribution of respondents who do not comply checks of blood glucose levels, it is possible because the majority of respondents (65.1\%) had a far distance from the house to the health service that sometimes make respondents reluctant to go examination of blood glucose levels.

The results are consistent with research conducted by Quarratuaeni (2009) at the General Hospital Fatmawati Jakarta stating that there is no correlation between education with uncontrolled blood glucose levels of patients with diabetes mellitus ( $\mathrm{p}=$ 0.903). As well as with research conducted at Perjan Isniati Polyclinic Dr. M. Djamil hospital, Padang in 2003 which concluded that there was no significant relationship between education fasting blood glucose controlled levels $(\mathrm{p}=0.850) 15$.

Domain knowledge is very important for the formation of a person's actions. Behavior, fueled by the knowledge will be more lasting than the behavior which is not motivated by knowledge. Good level of knowledge about diabetes mellitus, will allow the patient to have the correct perception of the risk of complications and the subsequent effect on measures to be taken for prevention. Based on the results of interviews on 93 respondents, there are 63 respondents who had experienced complications namely hypertension 18 people, 22 people neuropathy, stroke 2, dyslipidemia 18 and nephropathy 3.

Statistical test results between the variables knowledge disobedience Diabetes Mellitus in examinations of blood glucose obtained value of $\mathrm{p}=0.839$. This shows there is no correlation between knowledge of the non-compliance of patients with diabetes mellitus in examinations of blood glucose levels. This means that the high level of knowledge does not necessarily affect the behavior of patients to check blood glucose levels. Although knowledge is 
one factor expected to influence the behavior of someone in the act or to do something, but in this study did not fully checking blood glucose levels in patients with diabetes mellitus should be preceded by a good knowledge. This is in line with the theory put forward by Skinner in which health behaviors will grow from the desire of individuals to make efforts to preserve or maintain health in order not sick and attempts to perform a variety of treatments to use various health facilities7.

With the results of studies showing no correlation between knowledge with nonadherence checking blood glucose levels, according to researchers is because even if the patient has less knowledge, but there is a strong will inside the patient to heal, so that is the reason for them to check blood glucose levels. Another reason of the respondents who do not adherence examine blood glucose levels caused by the activity (office work) outside the region, lack of time due to various activities resulting respondents did not perform checks of blood glucose levels as recommended by your doctor.

The results are consistent with research Meydani (2011), which states there is no significant relationship between the level of knowledge and the prevention of complications of DM patients in the Specialty Clinic Internal Medicine Hospital Dr. M. Djamil Padang ( $\mathrm{p}=1.000) 16$.

The result of this study are not consistent with the research conducted by Rahmadiliyahni at Public Health Service 1 GatakSukoharjo in 2010 with 42 respondents that there is a significant relationship between knowledge about the disease and complications in diabetes mellitus patients to measures to control blood glucose levels.

It should be the enabling factor for this difference is the number of samples in previous studies less compared to this research so as to allow their differences in relation to non-adherence checks of blood glucose levels.

The result of the research showed the distance variable to the health service significant related to non-adherence of diabetes mellitus patients in measuring blood glucose level $(\mathrm{p}=0.005)$. The results of interviewing to 93 respondents, 55 residences away to health care and 35 respondents of 55 respondents who do not comply checking blood glucose levels. The non-adherence respondents to measuring the blood glucose levels caused of the residences away to the health care also the activity family members to take the respondents to the hospitals so it take long time to doctor for checking the patients. In addition, checking blood glucose with fasting which done in the morning should be adjusted to the length of fasting time and sometimes make lazy respondents because often preoccupied doing homework, and most them are housewives with 36 respondents of 93 .

Family supports help diabetes mellitus patients believe to increase their treatment. The diabetes mellitus patients with good environment will motivate the patients to have measuring the blood glucose levels.

This study showed that family support had significant relation to non-adherence of diabetes mellitus patients to measuring blood glucose levels $(p=0.043)$. Result of interviewing for 41 respondents said that there is no family support and 26 respondents of non-adherences diabetes mellitus patients to measuring blood glucose levels. Based on observations of researchers when the study most respondents, not accompanied by family members during the examination and consultation with a doctor, this is also affects the non-adherence of 
Indonesian Journal of Medicine (2016), 1(1): 12-19 https://doi.org/10.26911/theijmed.2016.01.01.02

patients to check blood glucose levels because the advice given by doctors to perform reassessment sometimes not be remembered by the patient due to the presence of memory loss, especially from the 93 respondents, 48 respondents who are elderly (aged over 60 years). In addition, based on interviews of 93 respondents only 5 respondents $(5.4 \%)$ who said that the reason they checking blood glucose levels because of the family advising, the majority (64.5\%) conduct checks of blood glucose levels because of doctors advising and other respondents (30.1\%) who did the examination because they want to know and control blood glucose levels.

This study based on the research conducted by Isworo (2010) which stated that there is a significant relationship between family support controlling blood glucose levels in patients with type two diabetes mellitus $(\mathrm{p}=0.005)$.

This study recommends that further research be conducted at Prof. dr. Z. W. Johannes Hospital, Kupang should make a diabetes mellitus patients controlled card so it make the patients control their examination time recorded on the controlled card easily.

Providing support to family members who are diabetes mellitus patients to always remind them to do checking their blood glucose levels regularly, also consume food in accordance with the schedule.

In addition providing health care close to the diabetes mellitus patients make the patient do their measuring blood glucose level easily and regularly.

\section{REFERENCE}

Ambari PKM (2010). Relationship Between Family Support and social functioning in Patients with Schizophrenia Post-
Care Hospital. Faculty of Psychology, Diponegoro University, Semarang.

Dinosetro (2008). Relationship Between The Role of Family Social Life with social Independence Level in Schizophrenia Post Client Care in Mental Menur Hospital. .http: //dinosetro.multiply.com/guestbook? \& = \& page $=3$. Date accessed 22/1/2013.

IDF(International Diabetes Federation). (2003). Diabetes and cardiovascular disease. http://www.idf.com.

Isniati (2003). Associated Diabetes Mellitus Level with Controlling Polyclinic Hospital Blood Glucose In Perjan Dr. M. Djamil, Padang. http://repository.ua.ac.id/pdf/5420127812 /6754210 date accessed 29/05/2013.

Isworo A (2010). Relationships Depression and Family Support to Controlling Blood Glucose in Patients with Type 2 Diabetes Mellitus in RSUD, Sragen. http:Accessible//www.library.upnvj.ac .id/pdf/4s1kedokteran/207311018/BA B\%20IV.pdf 31st / 05/2013.

Kemenkes (2009). Prevalence of Diabetes Mellitus. Jakarta: Ministry of Health RI.

Meydani YDP (2011). Factors Associated with Complications of Diabetes Mellitus Prevention Efforts by Diabetes Mellitus Patients in Internal Medicine Specialty Clinic Hospital Dr M. Djamil Padang.

Non-Communicable Disease Control Directorate (2008). Technical Guidelines for Discovery and Management of Diabetes Mellitus. Jakarta.

Quarratuaeni (2009). Factors Associated with Controlled Blood Sugar Levels in Patients with Diabetes Mellitus in Fatmawati General Hospital Jakarta.http://repository.uinjkt.ac.id/dispa ce/bitstream/123456789/597/1/9249 
6-QURRATUAENI-FKIK.pdfdate accessed 05/31/2013.

Rahmadiliyani N (2010). Relationship between Knowledge of Disease and Complications in Patients with Diabetes Mellitus Measures Controlling Blood Glucose Levels in Publich Health Service I Gatak Sukoharjo. http://www.library.upnvj.ac.id/pdf/4s 1kedokteran/207311018/BAB\%20IV.p df date accessed 31/05/2013.
Rizal NB (2008). Factors associated with the incidence of Coronary Heart Disease In Patients with Type 2 diabetes in DR. M. Djamil Padang. Essay. Padang: StudiIlmu Nursing Program UniversitasAndalasPadang.

Semana A (2011). Factors Associated with Adherence Medication Type II Diabetes Mellitus Patients in the District General Hospital Labuang Makassar Baji. 